\title{
PRODUKSI LIMBAH BONGGOL JAGUNG DI DESA SAENTIS
}

\author{
Ardhansyah Putra Hrp ${ }^{1}$ \\ ${ }^{1}$ Jurusan Akuntansi, Fakultas Ekonomi Universitas Muslim Nusantara Al Washliyah Medan \\ e-mail: ardhansyahputra@umnaw.ac.id
}

\begin{abstract}
Abstrak
Tujuan kegiatan ini untuk membantu penyelesaian permasalahan prioritas mitra agar mitra mampu menjadi mandiri dan mengarah ke ekonomi produktif dengan memanfaatkan limbah tongkol jagung. Mitra kegiatan PKM yaitu kelompok usaha petani jagung Desa Saentis yang berjarak $\pm 25 \mathrm{~km}$ atau 40 menit perjalanan normal dari Universitas Muslim Nusantara AlWashliyah. Permasalah prioritas mitra sebagai berikut; (1) aspek produksi, diantaranya; a) mitra belum memiliki pengetahuan dan keterampilan dalam mengolah tongkol jagung; b) mitra belum pernah diberikan pelatihan mengolah tongkol jagung dari pihak pemerintah maupun swasta; c) mitra belum memiliki teknologi tepat guna untuk mengolah tongkol jagung menjadi barang-barang kerajinan. Metode pelaksanaan menggunakan pendidikan dan penyuluhan, focus group discussion, pelatihan, praktek produksi, benchmarking, rancang bangun website $e$-commerce. Solusi permasalahan prioritas mitra dari: (1) aspek produksi, diantaranya: a) Focus Group Discussion potensi limbah jagung menjadi barang-barang kerajinan; b) penggunaan teknologi tepat guna berupa mesin grinda dan gergaji besi untuk membuat barang kerajinan dari tongkol jagung; c) Benchmarking mitra ke UKM pengrajin tongkol jagung; dan d) pelatihan mendesain barang-barang kerajinan berbahan tongkol jagung. Target luaran antara lain: 1) mesin grinda dan gergaji besi; 2) peningkatan keterampilan mitra dalam produksi barang kerajinan berbahan tongkol jagung; 3) desain barang-barang kerajinan berbahan tongkol jagung seperti tempat tisu, lampu hias, alas piring makan.
\end{abstract}

Kata Kunci: Pemanfaatan, Limbah Bonggol Jagung

\section{A. Pendahuluan}

Kabupaten Deli Serdang memiliki lahan pertanian yang luas, yakni lebih dari 30\% dari total wilayah. Umumnya lahan pertanian ditanami tanaman padi dan palawija seperti jagung, ubi jalar, ubi kayu, kacang tanah, kedelai, kacang hijau, dan sayuran. Kapasitas produksi jagung dari tahun 2013 sampai 2017 terus mengalami peningkatan melebih ubi jalar dan ubi kayu (BPS,2018).

Desa Saentis Kecamatan Percut Sei Tuan yang merupakan lokasi mitra PKM memiliki luas lahan sebesar 477 ha yang merupakan terbesar kedua di Kecamatan Percut Sei Tuan dengan produksi jagung sebesar 4.731,8 ton (BPS, 2018). Begitu banyaknya hasil panen jagung setiap tahunnya menghasilkan limbah pertanian seperti tongkol dan klobot yang 
Vol. 4 No. 1 April 2020

belum dapat dimaksimalkan oleh mitra. Rahmanto (2011) menjelaskan bahwa bobot berat tongkol jagung sebesar 10\% dari jagung. Sehingga dapat diperoleh informasi bahwa jika hasil panen jagung Desa Saentis di tahun 2017 sebesar 4.731,8 ton maka akan dihasilkan limbah tongkol jagung sebesar 473,18 ton. Limbah tongkol jagung tersebut merupakan nilai ekonomis yang belum dimanfaatkan oleh mitra.

Tabel 1. Luas Tanaman dan Produksi Tanaman Jagung Kecamatan Percut Sei Tuan

\begin{tabular}{|l|r|r|}
\hline Kecamatan & Lahan $(\mathrm{ha})$ & Produksi (ton) \\
\hline Amplas & 281,00 & $2.787,00$ \\
\hline Kenangan & - & - \\
\hline Tembung & 1,60 & 15,87 \\
\hline Sumber Rejo Timur & 29,00 & 287,00 \\
\hline Sei Rotan & 162,00 & $1.607,00$ \\
\hline Bandar Kalippa & 461,00 & $4.573,10$ \\
\hline Bandar Khalipa & - & - \\
\hline Medan Estate & - & - \\
\hline Laut Dendang & 5,00 & 79,36 \\
\hline Sampali & 242,00 & $2.400,64$ \\
\hline Bandar Setia & 11,00 & 109,10 \\
\hline Kolam & 811,00 & $8.045,00$ \\
\hline Saentis & 477,00 & $4.731,80$ \\
\hline Cinta Rakyat & - & - \\
\hline Cinta Damai & - & - \\
\hline Pematang Lalang & - & - \\
\hline Percut & - & - \\
\hline Tanjung Rejo & - & - \\
\hline Tanjung Selamat & - & - \\
\hline Kenangan Baru & - & - \\
\hline
\end{tabular}

Limbah pertanian yang secara rutin dihasilkan oleh petani jagung sering dipahami sebagai buangan sehingga menjadi beban yang memerlukan pengorbanan tertentu untuk membuang atau memusnahkannya. Diperlukan perubahan paradigma dalam memandang limbah pertanian, yakni dengan memahaminya sebagai produk sampingan yang memiliki nilai ekonomis. Limbah pertanian menjadi suatu potensi yang dapat dikelola menjadi produk yang bernilai ekonomis, seperti memberikan nilai tambah, menjadi sarana produksi pertanian dan membuka lapangan kerja baru. 


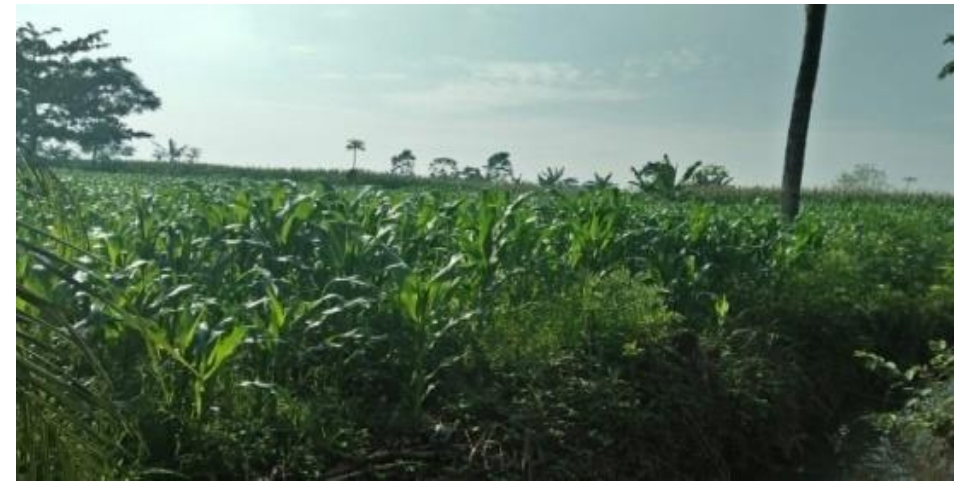

Gambar 1. Lahan Pertanian Jagung Desa Saentis (Harahap)

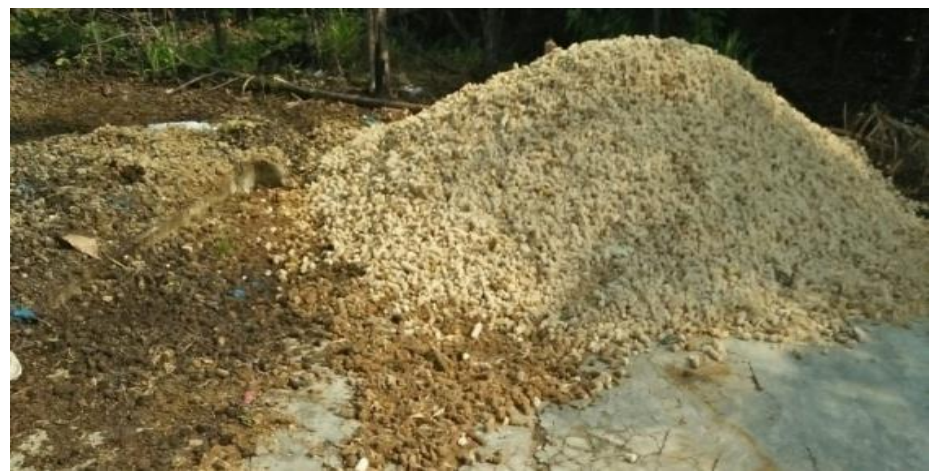

Gambar 2. Limbah Bonggol Jagung (Harahap)

Potensi limbah bonggol yang berlimpah berpotensi menjadi peluang usaha bagi mitra dengan mengolah tongkol jagung menjadi barang-barang kerajinan seperti tempat tisu, lampu hias, dan alas piring makan, sehingga diperlukan transfer pengetahuan dan keterampilan kepada kelompok petani jagung untuk memanfaatkan bonggol jagung. Pemanfaatan potensi limbah tersebut dapat mengakibatkan peningkatan pengetahuan dan keterampilan, peningkatan pendapatan masyarakat serta perbaikan kualitas lingkungan dengan mengolah limbah bonggol jagung secara berkelanjutan. Program-program pelatihan dan keterampilan produksi memanfaatkan potensi bonggol jagung diharapkan dapat menciptakan peluang usaha baru bagi mitra sehingga akan tercipta kelompok petani jagung mandiri secara ekonomi dan mengarah ke ekonomi produktif. 


\section{B. Masalah}

Berdasarkan diskusi dan wawancara langsung kepada mitra mengungkapkan masalah prioritas mitra yaitu aspek produksi. Adapun rincian permasalahan prioritas dari aspek produksi dijelaskan sebagai berikut;

a) Mitra belum memiliki pengetahuan dan keterampilan dapat mengolah tongkol jagung

b) Mitra belum pernah diberikan pelatihan mengolah tongkol jagung dari pihak pemerintah maupun swasta

c) Mitra belum memiliki teknologi tepat guna untuk mengolah tongkol jagung menjadi barang-barang kerajinan.

\section{Metode Pelaksanaan}

Metode pelaksanaan yang digunakan untuk penyelesaian masalah prioritas mitra antara lain; pendidikan dan penyuluhan. Kegiatan penyuluhan dilakukan dengan ceramah dan diskusi sekaligus praktek lapangan (LODM Mustari, Antasalam Ajo, Azelia Monica A, 2019). Focus group discussion, pelatihan, praktek produksi. Penggunaan metode pada permasalahan aspek produksi diuraikan pada tabel berikut.

Tabel 2. Metode Pelaksanaan Kegiatan

\begin{tabular}{|l|l|}
\hline \multicolumn{1}{|c|}{ Metode } & \multicolumn{1}{c|}{ Kegiatan } \\
\hline Pendidikan dan penyuluhan & $\begin{array}{l}\text { Focus Group Discussionpotensi limbah jagung menjadi } \\
\text { barang-barang kerajinan }\end{array}$ \\
\hline Praktek produksi & $\begin{array}{l}\text { Penggunaan teknologi tepat guna berupa mesin grinda dan } \\
\text { gergaji besi untuk membuat barang kerajinan dari bonggol } \\
\text { jagung }\end{array}$ \\
\hline Benchmarking & Benchmarking mitra ke UKM pengrajin bonggol jagung \\
\hline
\end{tabular}

\section{Pembahasan}

1. Pendidikan dan Penyuluhan Potensi Limbah

Kegiatan ini dilaksanakan pada tanggal 20 Juli 2019 bertempat dikantor kepala Desa Saentis dihadiri sebanyak 20 petani jagung. Kegiatan ini memaparkan potensi limbah jagung menjadi barang-barang yang memiliki nilai ekonomis. Beberapa barang kerajinan yang dapat asbak rokok, mangkuk, piring, dan lainnya. Para peserta sangat antusias mengikuti kegiatan Focus Group Discussion, hal ini ditandai dengan aktivitas diskusi tanya jawab dengan 
narasumber dan juga komitmen peserta untuk mengikuti rangkaian aktivitas pengabdian sampai program selesai.

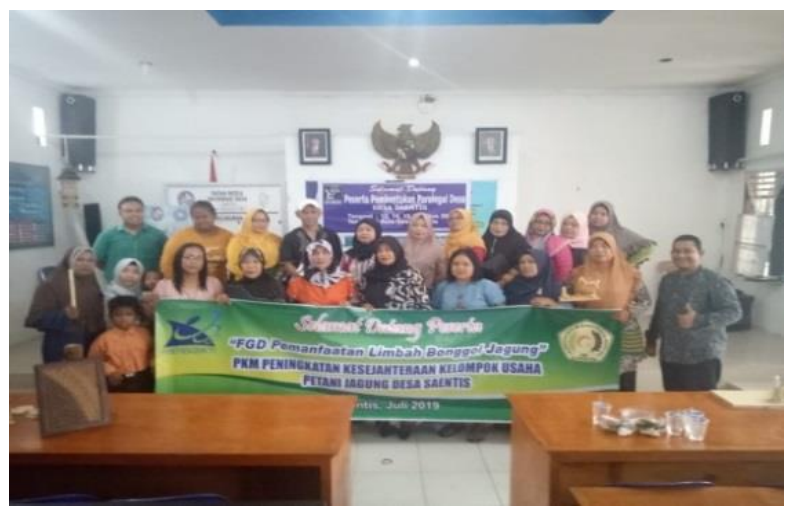

Gambar 3. Focus Group Discussion Pemanfaatan Limbah Bonggol Jagung

\section{Praktek Produksi}

Kegiatan ini dilaksanakan selama 7 hari mulai tanggal 01 sampai 07 Agustus 2019 bertempat di rumah produksi Bonggol Jagung yang bertempat di Kota Medan. Praktek produksi dilakukan dengan metode benchmarking, di mana para peserta belajar secara langsung kepada pengrajin bonggol jagung. Peserta sangat antusias dan telah memilki keterampilan produksi limbah bonggol jagung menjadi barang kerajinan. Akan tetapi, peralatan yang terbatas menjadi hambatan untuk produksi masal bagi petani jagung di Desa Saentis, sehingga diperlukan peran dari Pemerintah Desa Saentis untuk tanggap akan potensi lokal berupa limbah bonggol jagung dan keterampilan produksi barang kerajinan yang dapat dialokasikan pada Anggaran Dana Desa tahun 2020.

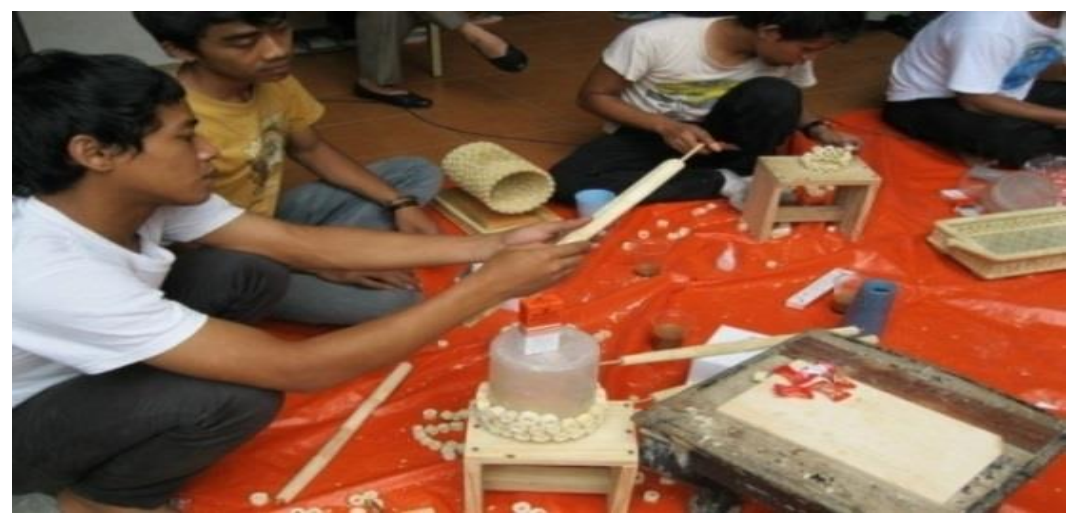

Gambar 4. Pelatihan Desain Barang Kerajinan Dari Bonggol Jagung 


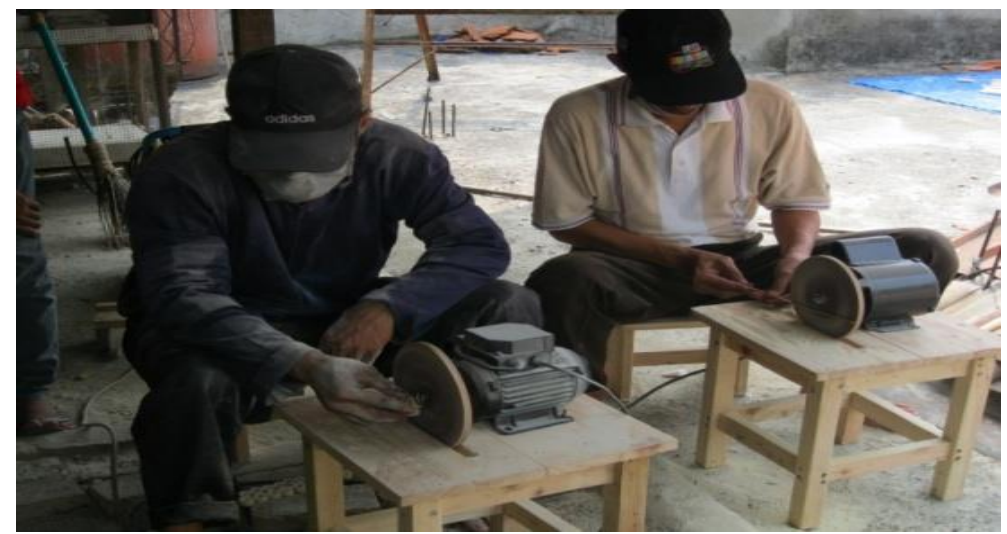

Gambar 5. Pelatihan Desain Barang Kerajinan Dari Bonggol Jagung

Kegiatan pengabdian ini menghasilkan luaran yang dicapai, antara lain:

1) Peningkatan keterampilan mitra dalam produksi barang kerajinan berbahan tongkol jagung

2) Desain barang-barang kerajinan berbahan tongkol jagung seperti tempat tisu, lampu hias, alas piring makan

3) Peningkatan pendapatan dan jenis produk mitra

\section{E. Kesimpulan}

Tujuan kegiatan ini yaitu untuk membantu penyelesaian permasalahan prioritas mitra agar mitra mampu menjadi mandiri dan mengarah ke ekonomi produktif dengan memanfaatkan limbah bonggol jagung. Permasalahan mitra dari segi aspek produksi yang diantaranya mitra belum memiliki pengetahuan dan keterampilan dalam mengolah bonggol jagung, mitra belum pernah diberikan pelatihan mengolah bonggol jagung dari pihak pemerintah maupun swasta, mitra belum memiliki teknologi tepat guna untuk mengolah tongkol jagung menjadi barang-barang kerajinan. Melalui kegiatan ini beberapa solusi dari permasalahan mitra yang telah dilakukan yaitu Focus Group Discussion potensi limbah jagung menjadi barang-barang kerajinan, penggunaan teknologi tepat guna berupa mesin grinda dan gergaji besi untuk membuat barang kerajinan dari bonggol jagung, benchmarking mitra ke UKM pengrajin bonggol jagung dan pelatihan mendesain barang-barang kerajinan berbahan tongkol jagung. Pemanfaatan potensi limbah tersebut dapat mengakibatkan peningkatan pengetahuan dan keterampilan, peningkatan pendapatan masyarakat serta perbaikan kualitas lingkungan. Melalui kegiatan ini juga diharapkan dapat menciptakan 
peluang usaha baru bagi mitra sehingga akan tercipta kelompok petani jagung mandiri secara ekonomi dan mengarah ke ekonomi produktif.

\section{DAFTAR PUSTAKA}

Badan Pusat Statistik Kabupaten Deli Serdang. (2018) Deli Serdang Dalam Angka, BPS Kabupaten Deli Serdang: CV. Rilis Grafika.

Badan Pusat Statistik Kabupaten Deli Serdang. (2018). Kecamatan Percut Sei Tuan Dalam Angka, BPS Kabupaten Deli Serdang: CV. Rilis Grafika.

LODM Mustari, Antasalam Ajo, Azelia Monica A, Hardin. (2019). Penyuluhan Laboratorum Lapangan Budidaya Terong Dan Cabe di Kelurahan Bandar Batauga Kecamatan Batauga Kabupaten Butonselatan. Jurnal Pengabdian Kepada Masyarakat MEMBANGUN NEGERI, 3(2), 36-47.

Rahmanto, M.I. (2011). Identifikasi Potensi Pemanfaatan Limbah Pertanian di Kabupaten Bekasi. Jurnal Agribisnis dan Pengembangan Wilayah. Vol. 2 No. 2. 